\title{
Feminismo estilo magazine: um estudo sobre a Revista Elle Brasil*
}

\author{
Juliano Borges** \\ Milena Coppi***
}

\section{Resumo}

O trabalho analisa duas edições da revista Elle Brasil que abordaram temáticas feministas em 2015. Destinada ao público feminino consumidor de moda, o feminismo foi incorporado à revista em aparente contradição com os conteúdos convencionais e valores afirmados em sua linha editorial. Porém, essa incorporação do feminismo não configura uma novidade, mas uma experiência de continuidade na história da imprensa feminina brasileira, a que chamamos de 'feminismo estilo magazine', pautada agora, porém, pela influência das redes sociais. Para compreender as ambiguidades e potencialidades políticas dessa dicotomia mobilizamos abordagens construcionistas em uma análise da revista como formadora de opinião.

Palavras-chave: Feminismo, Revista de Moda, Interseccionalidades, Teorias do Jornalismo, Redes Sociais.

* Recebido em 17 de novembro de 2018, aceito em 20 de maio de 2019.

** Jornalista (UFRJ) e doutor em Ciência Política (IUPERJ). Professor titular do IBMEC-RJ, Rio de Janeiro, RJ, Brasil. julianoborges@gmail.com / https://orcid.org/0000-0001-7592-8522

*** Jornalista freelancer com publicações em O Globo, Extra, Uol, Globoesporte.com e Reverb, Rio de Janeiro, RJ, Brasil. mcccoppi@gmail.com / https://orcid.org/0000-0002-8476-9874 
Magazine Style Feminism: A Study of the Elle Brasil

\begin{abstract}
The paper analyzes two editions of the Elle Brasil magazine that focused on feminist themes in 2015. Intended for female fashion consumers, feminism was incorporated to the magazine, in apparent contradiction with the conventional contents and values affirmed by its editorial line. This was not a novelty, but an experience of continuity that echoes the history of the Brazilian women's press. We call this 'magazine style feminism', which is now influenced by social media. To understand the ambiguities and political potential of this dichotomy, we used constructional approaches, based on an analysis of the magazine as an trendsetter.
\end{abstract}

Keywords: Feminism, Fashion Magazine, Intersectionalities, Journalism Theories, Social Media. 


\section{Introdução}

Em uma sociedade altamente midiatizada, a cultura é particularmente sujeita à ação dos meios de comunicação, que podem atuar reforçando estereótipos sociais ou contribuindo com perspectivas mais abertas, capazes de privilegiar a diversidade em sociedades complexas, vocalizando novos atores, pautas $e$ angulações, em sintonia com as transformações próprias de cada momento histórico.

Com base nessa premissa, este artigo pretende discutir o feminismo, sobretudo em sua forma de movimento cultural, quando transformado em produto da cultura em uma sociedade midiatizada (Orozco, 2006). Para isso, tomaremos como objeto de estudo as edições de maio (n. 234) e de dezembro de 2015 (n. 241) da revista Elle Brasil. Destinada ao público feminino consumidor de moda, a revista tratou, em ambas as edições, de temas que destoavam bastante de sua abordagem convencional e, em grande medida, de sua linha editorial, que segundo a revista, produz "luxo com atitude", é "irreverente, ousada e aposta no novo" (Mídia Kit Elle, 2017:3).

O que classificamos como 'feminismo estilo magazine' é o resultado da incorporação e da adequação de temas da agenda progressista feminista às características e aos constrangimentos editoriais comuns às chamadas glossy magazines, revistas femininas de luxo, dedicadas tradicionalmente à cobertura de moda, consumo e tendências de comportamento (Reed, 1998). Na conversão do feminismo em produto de cultura, Elle acomodou em suas páginas a diversidade de visões feministas tratando-as como uma tendência contemporânea inovadora e cheia de atitude.

Considerando essa hipótese como ponto de partida, estudada originalmente no início dos anos 1990 por Robert Goldman, Deborah Heath e Sharon Smith mobilizando o conceito de commodity feminism (Goldman; Heath; Smith, 1991), buscaremos encontrar as motivações que levaram a revista a escolher o tema do feminismo em duas edições especiais, e de que 
maneira ele foi tratado. Notamos, ainda, que a incorporação do feminismo como objeto de revistas femininas não configura propriamente uma novidade, quando antes aparece como um episódio desse fenômeno na história da imprensa feminina brasileira (Duarte, 2016), pautada agora, porém, pela influência das interações ocorridas nas redes sociais.

Para compreender essa relação aparentemente contraditória, este artigo explora que aspectos relacionais da identidade social são articulados pela imprensa destinada ao público feminino em um contexto de cultura de massas. Para isso, empregaremos uma perspectiva feminista de tipo interseccional a partir dos aportes de Avtar Brah, que contribuem com categorias diversas para além do gênero no entendimento da articulação das diferenças. O objetivo é compreender como essas diferenças podem se articular de maneira dinâmica, complexa $e$ frequentemente contraditória.

$\mathrm{Na}$ segunda parte do artigo, discutiremos o papel das revistas e a noção de segmentação de mercado para, em seguida, caracterizarmos a revista Elle. Nesta seção, a linha editorial e os conteúdos da revista merecerão atenção, observados pela perspectiva construcionista do jornalismo, que compreende a notícia como um resultado das práticas profissionais em interação construtiva e mútua com a realidade social que o engloba. Por fim, realizamos uma avaliação analítica do objeto, considerando três elementos: perfil; conteúdos; e abordagens e vieses, em que avaliaremos o tratamento editorial conferido por Elle Brasil ao feminismo para compreender as razões $e$ reconhecer os procedimentos que levaram a revista a assumir questões feministas como pautas importantes de duas edições temáticas especiais. Estaria Elle mais sensivel aos problemas concretos enfrentados por suas leitoras, ou o feminismo foi submetido a um processo de esvaziamento da sua dimensão contestatória ao ser convertido em um produto de massa? É possível que as alternativas não sejam excludentes? É o que buscaremos compreender. 


\section{Dominação, identidade e diferença}

A importância política e cultural do feminismo é apontada por Stuart Hall (2014) como um dos fatores do descentramento histórico experimentado pela identidade na pós-modernidade. Segundo Hall, enquanto o sujeito da sociedade moderna era possuidor de um lugar bem determinado, tanto social quanto culturalmente, o sujeito pós-moderno experimenta uma série de mudanças estruturais que trazem questionamentos quanto às identidades culturais de classe, raça, sexo, nacionalidade e etnia.

Uma das contribuições do feminismo foi justamente a de problematizar a exclusão das mulheres como sujeitos que compartilham essas características identitárias racionais $e$ científicas, consagradas na separação público-privado. $\mathrm{O}$ Iluminismo universalizou o sujeito masculino operando, assim, uma exclusão das mulheres do espaço público (e da política, em especial) e da possibilidade de autonomia, relegando-as ao espaço privado e à condição de objeto ${ }^{1}$.

Hall aponta que o feminismo teve relação direta com o descentramento conceitual dos sujeitos cartesiano e sociológico ao questionar a distinção entre público e privado, contestar politicamente a vida social, politizar a subjetividade, a identidade $e$ o processo de identificação. Nesse contexto, é possível afirmar que o movimento feminista foi central ao colocar em pauta o papel da mulher na sociedade. Ainda que inicialmente a contribuição do feminismo tenha se concentrado na proposição do gênero como categoria a partir de uma perspectiva eminentemente ocidental, logo outras categorias como sexo, classe social e raça foram

\footnotetext{
${ }^{1}$ Dado que este conceito tem sido criticado pelas teorias feministas e de gênero (Cahill, 2012), cabe apontar que entendemos objetificação como efeito produzido pelas relações patriarcais de esvaziamento de agências femininas, tais como autonomia, valor próprio e controle sobre o corpo; que se traduzem em fenômenos sociológicos como violência sexual, representações hipersexualizadas das mulheres e a forma como as políticas reprodutivas são estruturadas, por exemplo. (Nussbaum, 1995)
} 
também mobilizadas para dar conta de entender a diversidade das próprias mulheres em um contexto mais amplo ${ }^{2}$.

De fato, os estudos culturais forneceram uma notável contribuição teórica ao explorar a articulação entre diferentes categorias de pertencimento e de subordinação que formariam uma estrutura abrangente constituída a partir de semelhanças $e$ diferenças (Kellner, 2001). Compreender os mecanismos de articulação dessas categorias e a natureza da relação entre elas, sem o pressuposto da sobredeterminação da esfera econômica, conforme uma tradição marxista, permite um entendimento mais complexo da dinâmica da formação social. É levando adiante essa proposição que Avtar Brah (2006) tomará a subjetividade e a identidade como elementos constitutivos das assimetrias políticas que permeiam a sociedade. Para dar conta dessa tarefa, ela abre mão da primazia do gênero como categoria analítica, privilegiando a ideia de 'diferença'.

Aqui o foco analítico está colocado na construção social de diferentes categorias de mulheres dentro dos processos estruturais e ideológicos mais amplos. Não se afirma que uma categoria individual é internamente homogênea. Mulheres de classe trabalhadora, por exemplo, compreende grupos muito diferentes de pessoas tanto dentro quanto entre diferentes formações sociais. A posição de classe assinala certas comunalidades de resultados sociais, mas a classe se articula com outros eixos de diferenciação como o

\footnotetext{
${ }^{2} \mathrm{Na}$ demarcação convencional que tenta dar conta do desenvolvimento do movimento feminista a partir de três etapas ou ondas, a primeira, conhecida como emancipacionista, teria surgido no fim do século do XIX como luta de caráter liberal contra a discriminação das mulheres e pela igualdade de direitos civis, políticos (direito ao voto) e educativos, antes reservados apenas aos homens. É somente a partir da segunda onda, já na década de 1960, que questões que como diferença (entre homens, mas também entre as próprias mulheres) e alteridade se colocam, ganhando novos contornos a partir dos anos 1980, quando questões como raça, sexo e classe social ganham mais relevo no debate feminista (Narvaz; Koller, 2006:649). Ainda que controversa, a demarcação expressa a progressiva complexificação do debate feminista ao longo do século XX.
} 
racismo, o heterossexismo ou a casta no delineamento de formas variáveis de oportunidades de vida para categorias específicas de mulheres (Brah, 2006:341-342).

Seu objetivo é compreender como os discursos se constituem sobre as diferenças (entendidas como experiência, relação social, subjetividade e identidade) e de como podem ser, a partir daí, reproduzidos, ressignificados ou rechaçados. Outras feministas ligadas a correntes pós-coloniais como Chandra Mohanty e Ella Shohat já haviam assinalado sua insatisfação com análises centradas sobre gênero, frequentemente afetadas por perspectivas essencialistas, destacando que outras categorias como nacionalidade e religião, além de raça, sexualidade e classe precisavam ser contempladas de forma articulada para responder ao nível de complexidade de uma realidade crescentemente fragmentada (Piscitelli, 2008).

A variedade de diferenças considerada de forma conjunta $e$ não hierarquizada a partir de uma ou outra categoria permite perceber os resultados da interação das diversas formas de dominação sem necessariamente assumir a perspectiva da superposição de subordinações. A abordagem construcionista no debate feminista observa os aspectos relacionais das diferenças, compreendendo-os de maneira articulada, cujo produto contribui para a definição de identidades sociais, passíveis de serem alteradas, portanto, como resultado prático desses processos articulatórios. O sentido gramsciano de hegemonia, marcante na leitura dos estudos culturais, ganha aqui outro impulso ao valorizar a possibilidade de reconfigurações políticas a partir da construção de novas identidades capazes de prover meios alternativos de ação. As interseccionalidades, na perspectiva construcionista, não se limitam assim a desvelar as formas de violência simbólica sofridas pelos diversos eixos de subordinação (sexismo, racismo, exploração do trabalho, xenofobia etc.). Como as categorias são percebidas como constituídas por meio das relações entre elas, articuladamente, as diferenças não são necessariamente equivalentes, podendo ser cumulativas, mas também mesmo 
contraditórias. E é justamente investindo contra essas contradições que se encontram as possibilidades de produzir estratégias antihegemônicas de luta.

Uma vez que a constituição de identidades nas sociedades contemporâneas é incidida crescentemente por fluxos midiáticos, que colaboram culturalmente na configuração de formas de agir e de pensar utilizando um conjunto de aparatos comunicacionais, buscamos compreender como as diferenças são apresentadas $e$ mobilizadas pelos meios de comunicação. Contudo, interessa-nos entender também as possíveis contradições $e$ ambiguidades que essas operações discursivas engendram. As revistas femininas, em geral, e Elle, em particular, fornecem um rico material para localizar historicamente esses processos, os quais serão analisados contando também com outro referencial construcionista, este próprio da teoria do jornalismo.

\section{Revistas femininas e representações da mulher}

Na obra "Jornalismo de revista", Marília Scalzo (2014:11) discorre sobre a prática jornalística em revistas e classifica este veículo de comunicação como "um produto, um negócio, um objeto, um conjunto de serviços, uma mistura de jornalismo $e$ entretenimento". Para seus leitores, entretanto, a revista pode estar revestida de significados mais subjetivos. Apesar de as tecnologias multimídias predominarem na atualidade, o texto ainda é a forma mais segura para a comunicação de conteúdos complexos, objetivo das revistas desde sua origem, para além da simples transmissão de notícias. De fato, na história das revistas nota-se menos sua vocação noticiosa e mais a afirmação de dois caminhos: o da educação e o do entretenimento. Elas "entretêm, trazem análise, reflexão, concentração e experiência de leitura" (Scalzo, 2014:13). De acordo com Scalzo, "revista une e funde entretenimento, educação, serviço e interpretação dos acontecimentos". A linguagem utilizada é coloquial e os enunciados são construídos de forma a criar intimidade com esse leitor, produzindo um efeito de subjetividade, diferentemente do 
jornal, que opera com o pressuposto do distanciamento e da objetividade jornalística. A subjetividade da linguagem proporciona um encontro simbólico entre o editor $e$ o leitor e essa cumplicidade é capaz de constituir fidelidade à revista e identidade entre seu grupo de leitores.

A segmentação de revistas para o público feminino também produz efeitos culturais próprios, em especial os que incidem sobre a construção simbólica do sentido de feminilidade. Tendo como base a separação entre mundo público $e$ vida privada, o feminino foi historicamente engendrado no universo dos sentimentos e dos sentidos; da beleza e da juventude; da domesticidade e da inaptidão para a vida pública; do vínculo com a família e com a maternidade (Lima; Said, 2018). Dulcilia Buitoni discorre sobre a imprensa voltada para as mulheres e a define como um produto definitivamente sexuado, baseado no sexo biológico ao qual seu público pertence. Para a autora, as revistas femininas contribuem para reforçar o pessoal em detrimento do social, esvaziando questionamentos políticos importantes $e$ incentivando o individualismo, o conforto dos bens materiais, a aquisição de coisas supérfluas como qualquer outro produto de comunicação de massa (Buitoni, 1986:69). Ironicamente, Buitoni acrescenta:

\begin{abstract}
A revista precisa gratificar sua consumidora e não enchê-la de preocupações. As publicações brasileiras, sempre mais tímidas, raramente se posicionam enquanto órgão de comunicação. Não trazem editoriais; a opinião, quando aparece, está nos textos assinados por colaboradores. A jornalista da imprensa feminina também evita se posicionar; socorre da opinião de especialistas que tem o respaldo de seu conhecimento (Buitoni, $1986: 71$ ).
\end{abstract}

Aqui talvez seja necessária uma digressão crítica a essa perspectiva. Embora o foco nas revistas femininas permita entendê-las como um espaço que se apóia e que explora as diferenças e assimetrias políticas entre homens e mulheres, já não seria correto estender esse traço para o conjunto da imprensa feminina. Outros trabalhos demarcam que no Brasil, desde o 
século XIX, a imprensa feminina é marcada por uma dicotomia entre a perspectiva antipolítica ressaltada por Buitoni $e$ a coexistência de um intenso ativismo jornalístico feminista; seja em periódicos próprios, seja através de atuações editoriais em órgãos de perfil conservador, caso do Jornal das Famílias, de 1863 (Duarte, 2016:165). Sobretudo a partir da segunda metade daquele século, o discurso emancipacionista, a defesa da instrução para mulheres e a consciência de seu valor para a sociedade encontram espaço em uma gama de folhas de caráter feminista, que conviverão lado a lado com periódicos de puro entretenimento não preocupados em questionar as desigualdades vigentes, relegando à mulher um papel passivo. A imprensa feminina, desde sua origem e ao longo do século $\mathrm{XX}$, abarca uma complexidade menos expressiva no formato de revistas, mas nem por isso inexistente. Ana Paula Bandeira lembra que historicamente nessas publicações

\begin{abstract}
mesmo hasteando a bandeira dos direitos e do crescimento intelectual da mulher, o discurso esteve sempre muito próximo a esforços com o intuito de reforçar o papel da mulher enquanto mãe, esposa ou dona de casa, (...) papéis atribuídos à mulher - característica que aproxima o jornalismo feminista de muitas das publicações do jornalismo feminino (Bandeira, 2015:195).
\end{abstract}

Veremos que edições de Elle podem reproduzir o cruzamento desses eixos políticos, o emancipatório e o conservador, que prescreve atributos e papéis ideais para a mulher. Majoritariamente, as revistas femininas excluem as mais diversas formas de representatividade, quase sempre apresentando um estilo de mulher ideal: jovem, magra, loura, alta, branca e de classe média, embora atinja um público segmentado, o que é fundamental para a publicidade (Swain, 2001). Enquanto a publicidade em outras mídias está ligada à duração temporal, nas revistas ela é atemporal e por isso mesmo muito lucrativa. Dessa forma, os periódicos anunciam mercadorias visando à criação ou reforço de hábitos de consumo. O desenvolvimento da fotografia, 
por exemplo, foi crucial para que os hábitos de consumo fossem reforçados $e$ as revistas de moda assumissem um apelo mais persuasivo e menos informativo no sentido político.

Editadas com grande freqüência por mulheres, interlocutoras do pensamento feminino para um público amplo, as revistas femininas surgiram no mundo ocidental no fim do século XVII e traziam em seu próprio título a distinção de gênero, a exemplo de Elle ('ela', em francês). Desde o início os temas abordados pela imprensa feminina continuam a ser repetidos como em uma fórmula editorial. As publicações ainda se dedicam a trazer temas como moda, beleza, culinária, casa e decoração, $e$ mesmo a linguagem pouco mudou com o passar dos anos. Ainda emprega-se formulação mais pessoal e afetiva, muito próxima da linguagem publicitária, sedutora, persuasiva, geradora de influência ("Love-se"; "Liberte-se"; "Divirta-se", como a capa de Elle da edição de maio de 2015). Dessa forma, é comum que matérias se pareçam e se confundam com anúncios, assim como os anúncios podem vir a ser facilmente confundidos com os conteúdos jornalísticos produzidos pela revista.

Pelo menos desde os anos 1980, esse vínculo entre conteúdo jornalístico e publicitário foi capaz de explorar o movimento feminista como um produto - commodity feminism (Goldmann; Heath; Smith, 1991). Em lugar de confrontar os questionamentos feministas, publicitários e editores de revistas femininas são capazes de extrair alguns de seus aspectos (como a autonomia da mulher e seu direito ao próprio corpo e à sexualidade), convertendo-os em signos logo associados ao produto revista $e$ às marcas ali anunciadas. As diversas facetas do feminismo que aparecem em revistas femininas se configuram, nesse contexto, em um aspecto contraditório da apropriação discursiva, que se expressa na forma de uma dialética entre o discurso hegemônico e o contestatório.

Uma das características hegemônicas de revistas femininas, por exemplo, é o aconselhamento voltado para a conquista de objetivos, em geral relacionados ao corpo, à beleza e à carreira (estes na chave motivacional de coaches). Esse aspecto não se 
distingue muito dos posts patrocinados produzidos por muitas blogueiras e influenciadoras digitais que fazem uso das redes sociais para autopromoção de sua imagem (ela própria um produto) para vender mercadorias e serviços (Karhwai, 2016). Embora suponham a mulher como sujeito, as revistas femininas com freqüência a tratam como objeto, fornecendo modelos (palavra que nesse contexto adquire variada dimensão semântica) que explicam normatizando como se comportar, o que vestir, que produtos comprar, enfim, como agir para ser uma "verdadeira mulher".

No contexto contemporâneo, trocam as receitas culinárias por receitas de vida, apoiando-se sobre a ausência relativa de autonomia feminina para produzir uma pedagogia destinada a ensinar a mulher a enfrentar a vida pública, sobretudo a profissional, sem que isso signifique uma alteração de seu papel tradicional na divisão "natural" do trabalho. Esta é outra perspectiva que pode ser questionada, sobretudo se cotejarmos a variedade de experiências que o jornalismo de revista encontra em espaços online. Revistas brasileiras independentes como Capitolina, AZmina e Lado $\mathrm{M}$, por exemplo, expressam representações da mulher muito distintas deste modelo tradicional atualizado, voltado para uma emancipação para o/no mercado (Silva, 2016). Nelas, o questionamento do 'padrão irreal' (de beleza, de consumo, de comportamento) e a contraposição ao 'correio sentimental', tão próprio das revistas femininas tradicionais, se constituem como estratégias políticas de construção de novas subjetividades femininas, em uma chave francamente contestatória do padrão hegemônico.

Quanto à factualidade, ela não é muito presente na imprensa feminina. Porém, em uma revista como Elle, que aborda sobretudo conteúdo de moda, a atualidade torna-se um compromisso necessário, ainda que de um tipo particular. Ela tem relação com os acontecimentos cotidianos, mesmo que apenas de forma latente. A revista (ou a indústria, a publicidade) cria um modismo apresentado como o que existe de mais atual. Dessa forma, imprensa feminina tradicional e moda se encaixam 
perfeitamente, uma alimentando a outra. No contexto das mídias digitais, entretanto, essa relação é complexificada porque os modismos não obedecem à mesma primazia criativa da indústria $e$ da publicidade de outrora. Com as redes sociais, os temas ali suscitados passam a ter um peso maior para pautar os assuntos abordados pelo jornalismo e, consequentemente, também pela moda. Na busca por ser útil ao seu leitor $e$ apresentar um conteúdo personalizado, a revista feminina precisa incorporar cada movimentação cultural (Tomazetti, 2015) para não ficar em descompasso na concorrência com as mídias digitais concorrentes (uma das motivações do encerramento de Elle Brasil, aliás).

Nesse contexto, as redes sociais tornam-se fonte que exerce influência crescente na decisão das pautas jornalísticas. É necessário lidar com a realidade concreta, em que a amplificação de discursos feministas ganha espaços articulados com a vocalização proporcionada pelas redes sociais.

\section{Elle, atualidade e feminismo estilo magazine}

O formato editorial convencional próprio da abordagem conservadora das revistas femininas coloca-se frequentemente em contradição com as transformações propostas pelas principais vertentes feministas, marcadas por uma agenda promotora de autonomia e afirmação feminina; questionadora do silenciamento $e$ das opressões às mulheres; de problematização do corpo e da sexualidade, do gênero e da identidade. Porém, a adequação de temas dessa agenda progressista às características editoriais típicas de revistas dedicadas à cobertura de moda resultou em edições de feminismo estilo magazine por Elle Brasil. Traçaremos a seguir os perfis da publicação e de seu público leitor.

Fundada em Paris, em 1945, por Pierre Lazareff e sua esposa Hélène Gordon, Elle é a maior publicação de moda luxo do mundo e está presente em mais de 45 países, vendendo cerca de 6,5 milhões de exemplares por mês. Segundo a definição presente no site da editora Abril, responsável pela publicação e produção da revista no Brasil, Elle é "irreverente, ousada e aposta 
no novo. Aborda a moda de forma jovem e inovadora" (Mídia Kit Elle, 2017).

Depois de 30 anos no país a revista encerrou sua publicação no Brasil, tanto impressa quanto online, em agosto de 2018, em meio aos sérios problemas financeiros enfrentados pela editora Abril, detentora dos direitos locais de publicação. Porém, em 25 de maio 2020, a revista voltou a ser publicada digitalmente, em um projeto multiplataforma liderado pela jornalista Suzana Barbosa e financiado pelo grupo Papaki. A versão física da nova Elle Brasil é esperada para o segundo semestre. Enquanto isso, a publicação se dedica a alimentar seu site, as redes sociais, com destaque para o Instagram, e o podcast batizado de "Pivô".

Até que fosse encerrada, no entanto, a revista possuía 173 mil leitores e vendia 43 mil exemplares por mês. Publicada no Brasil desde 1988, tinha periodicidade mensal e custava $\mathrm{R} \$ 18 \mathrm{em}$ junho de 2017. No quesito idade, $61 \%$ dos leitores tinham entre 18 e 30 anos. Quanto ao perfil social, $59 \%$ dos leitores pertenciam às classes $\mathrm{A}$ e $\mathrm{B}$, sendo majoritariamente mulheres (73\%). Os dados ainda indicam que $40 \%$ dos seus leitores faziam compras para relaxar e $43 \%$ pediam conselhos antes de fazer compras (Media Kit Elle, 2017).

Assim, podemos afirmar que o cerne do público-alvo de Elle era composto por jovens mulheres de classes média e alta, consumidoras efetivas e em potencial dos produtos de luxo ali anunciados, e inferir que fossem majoritariamente brancas, com certo nível de instrução e renda. Baseado também no caráter heteronormativo da publicação é possível inferir ainda que suas leitoras fossem de maioria heterossexual.

Considerando a relação utilitária própria das revistas femininas, os interesses desse público podem ser presumidos tanto pelas pautas quanto pelos anúncios, que compõem cerca de 1/3 do conteúdo total da revista. Chama a atenção que praticamente toda essa publicidade se restrinja a produtos de apenas dois ramos da economia: beleza e moda, sobretudo a de luxo (perfumes $e$ cosméticos; jóias e acessórios; roupas e sapatos). A crítica feminista à prescrição de formas corporais e ideais de beleza e à 
padronização e alienação pelo consumo (Wolf,1992); e o apelo à luta coletiva contra o ímpeto de realização individual, por parte de segmentos do movimento, entra aqui em claro conflito com Elle e sua proposta editorial.

Para se adequar à concorrência com as mídias digitais, as revistas femininas nos últimos dez anos vêm buscando repensar desde o seu formato físico até a escolha de suas pautas. Passaram a ter dois tipos de assinatura: a física e a digital, além de criarem perfis em redes sociais como Facebook e Instagram, por possuírem um aspecto mais visual do que outras redes como o Twitter. A revista Elle, em particular, também se orgulhava de ser a primeira publicação brasileira de moda a ter um site e uma versão digital própria para tablets (Media Kit Elle, 2017). O investimento em tecnologias pela revista passou ainda pelo uso de drones para fotografar editoriais de moda e vídeos produzidos especialmente para o aplicativo ElleTV, com promessa de efeitos de realidade aumentada a partir da visualização em aparelhos celulares.

\section{O contexto cultural}

De fato, as novas tecnologias da comunicação provocaram mudanças importantes no mercado editorial. Não só por permitirem formas alternativas de veiculação de conteúdos e de comunicação com seus leitores, mas também por produzirem interferências externas no interior das redações. Entre 2013 e o ano de 2015, quando as edições de maio e dezembro da revista Elle foram lançadas, os movimentos feministas obtiveram considerável visibilidade em espaços que até então os negligenciavam, como revistas de moda e campanhas publicitárias, ainda que de formas muitas vezes questionáveis. Em setembro de 2014, por exemplo, a grife francesa de alta costura Chanel levou para seu desfile de primavera-verão modelos encenando na passarela uma militância por causas feministas. A grife também trouxe estampas psicodélicas e símbolos da paz, que lembravam a moda hippie dos anos 1970, momento em que os costumes sexuais foram questionados. 
No Brasil, em 25 de outubro de 2015, o tema escolhido para redação do Exame Nacional do Ensino Médio foi "A persistência da violência contra a mulher na sociedade brasileira". A prova do vestibular cobrou também questões sobre Simone de Beauvoir. Em novembro daquele mesmo ano, o ato "Mulheres Contra Cunha" reuniu manifestantes em todo Brasil em defesa dos direitos das mulheres contra o então presidente da Câmara dos Deputados, Eduardo Cunha, e contra o Projeto de Lei 5.069, que dificultava o acesso à pílula do dia seguinte e obrigava as vítimas de estupro a passarem por exame de corpo de delito antes de poderem recorrer ao aborto na rede pública de saúde. As manifestações também chamaram atenção para a questão da vulnerabilidade social das mulheres pobres, negras e moradoras da periferia, já que também em 2015 o Mapa da Violência divulgou que o feminicídio de negras cresceu $54 \%$ em 10 anos, entre 2003 e 2013, enquanto o número de mulheres brancas mortas caiu $10 \%$ no mesmo período.

$\mathrm{O}$ ativismo na internet também teve protagonismo na divulgação de iniciativas feministas em 2015. Naquele momento, o coletivo brasileiro Think Olga buscava produzir o documentário "Chega de fiu-fiu" através de financiamento coletivo, e divulgava a campanha \#PrimeiroAssédio, para que mulheres e homens relatassem suas experiências, com intuito de debater o assédio virtual e coibir a prática. Em abril de 2014, surgiu a revista online independente Capitolina, criada por jovens que sentiam falta de ter suas experiências representadas na mídia para este público. Blogs como Lugar de Mulher e Gorda\&Sapatão e a youtuber Julia Tolezano, do canal JoutJout Prazer, também ajudaram a levar a diversidade de pautas do feminismo para muitas mulheres que talvez não conhecessem ou que não poderiam saber do movimento através de outros meios de comunicação.

Foi nesse contexto de expansão de visibilidade de pautas feministas que a revista Elle abordou a diversidade como tema de sua edição de aniversário, em maio de 2015. Procederemos agora, de forma mais detida, à análise dos conteúdos e abordagens das duas edições apontadas. 
Embora o termo "feminista" não estivesse presente, a revista incorporou a luta contra a imposição de padrões de beleza e a questão do corpo da mulher, pontos caros à agenda feminista, como temas centrais daquela edição. Para compor a capa e o editorial principal, a revista convidou modelos pouco convencionais para este tipo de publicação - uma mulher gorda (capa A), uma negra (capa B), outra albina (capa C), uma que incorpora traços andrógenos, uma mulher de meia idade e uma nordestina com traços indígenas - que participaram do especial "Bonito é ser diferente".

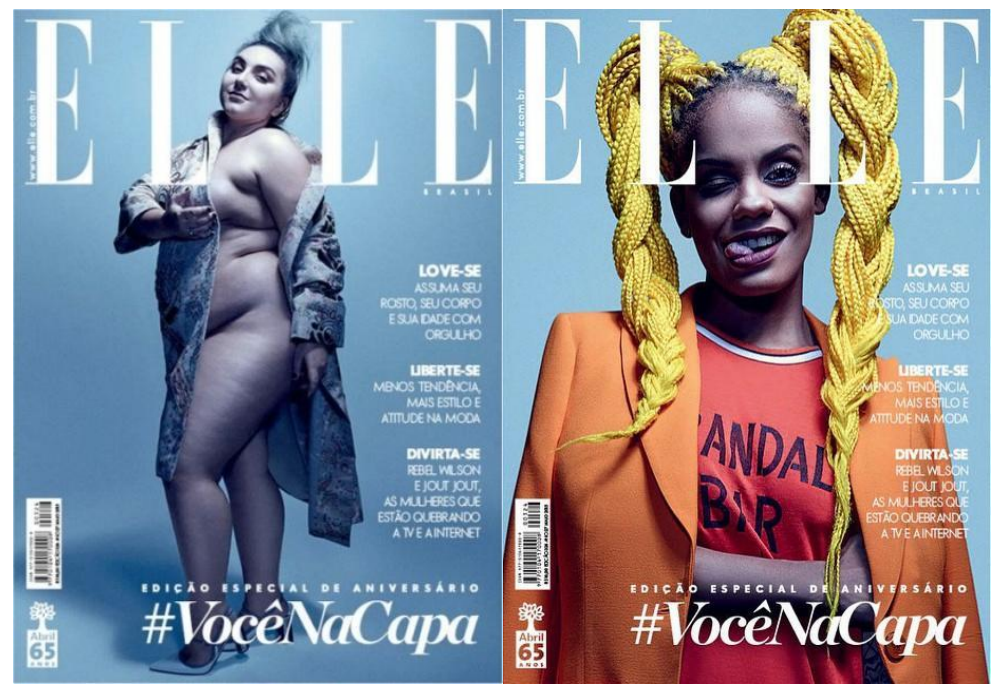

Capa A, maio/2015; Capa B, maio/2015 


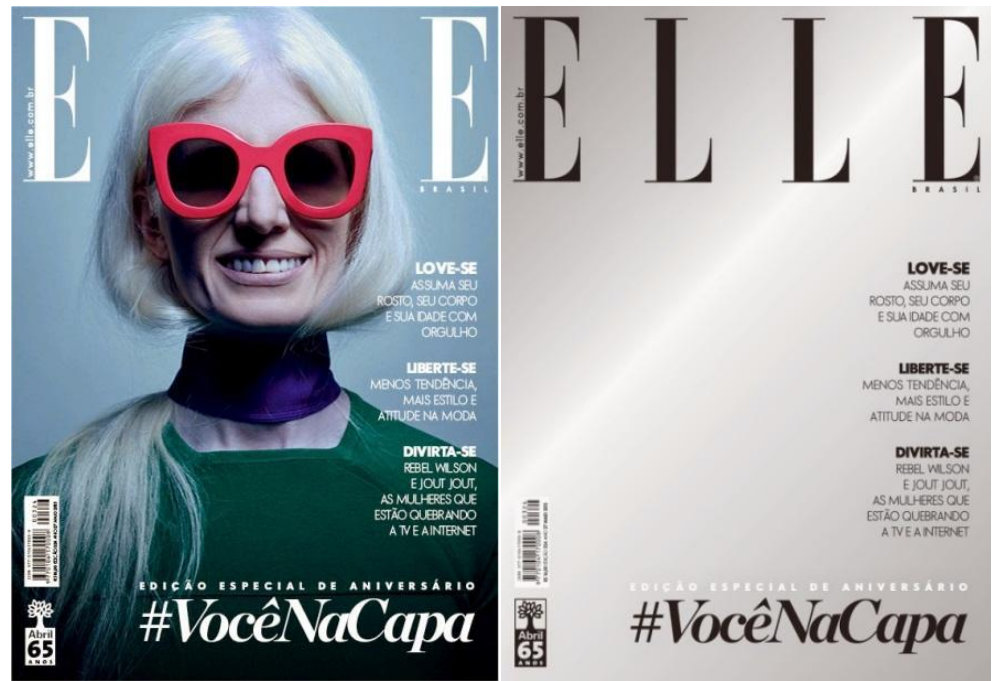

Capa C, maio/2015; Capa D, maio/2015

Outra novidade foi uma quinta opção de capa, na qual Elle investiu em um material espelhado (capa D). A ideia era que suas leitoras pudessem se ver na capa da revista, e que compartilhassem o resultado nas redes com a hashtag \#VocêNaCapa. No conjunto daquela publicação, entretanto, houve apenas seis matérias cujos temas se alinhavam de alguma forma a temáticas feministas ${ }^{3}$ enquanto as outras 50 matérias repetiam a velha fórmula das revistas de moda femininas. Destaca-se o fato desta edição, apesar de focar em autoestima e empoderamento, não conseguir ser majoritariamente dedicada ao

\footnotetext{
${ }^{3}$ A reportagem "Love-se", das jornalistas Sandra Soares e Camila Holpert, sobre investimento na autoestima feminina; o editorial fotográfico "Bonito é ser diferente", com imagens de Gustavo Lacerda, exibindo oito mulheres que prometem quebrar os padrões de beleza; a reportagem "Garota rebelde", de Lorraine Candy, com a atriz americana e feminista Rebel Wilson; a reportagem "JoutJout, a Lena Dunhan brasileira", de Mariana Marçal e Nana Caetano, sobre a youtuber feminista Julia Tolezano; a reportagem "O X da questão", de Renata Piza, sobre mulheres idosas que estão redefinindo a ideia de que só os jovens são felizes; e a reportagem "É tudo família", de Sandra Soares, sobre os novos arranjos familiares.
} 
assunto, e nem afirmar em qualquer momento a palavra "feminismo" ou termos correlatos.

Já em dezembro do mesmo ano, Elle avançou da temática da diversidade para uma edição especial declaradamente feminista. Para tal, formulou quatro capas - todas elas, no entanto, com modelos magras e jovens, apesar de tentarem representar quatro tipos de "belezas possíveis" - com as frases: "Vestida ou pelada, quero ser respeitada", "Meu decote não dá direitos", "Meu corpo, minhas regras", "Minha roupa não é um convite", recolhidas das manifestações políticas que tomaram as ruas em 2015.

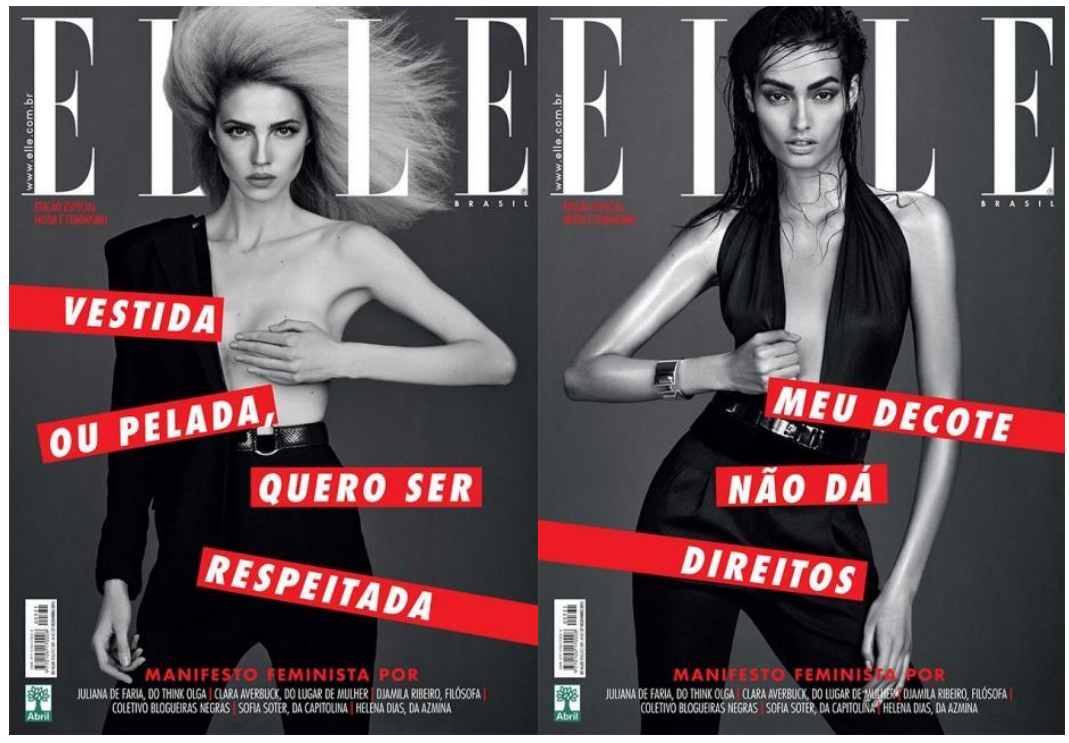

Capa A dez./2015; capa B dez./2015 


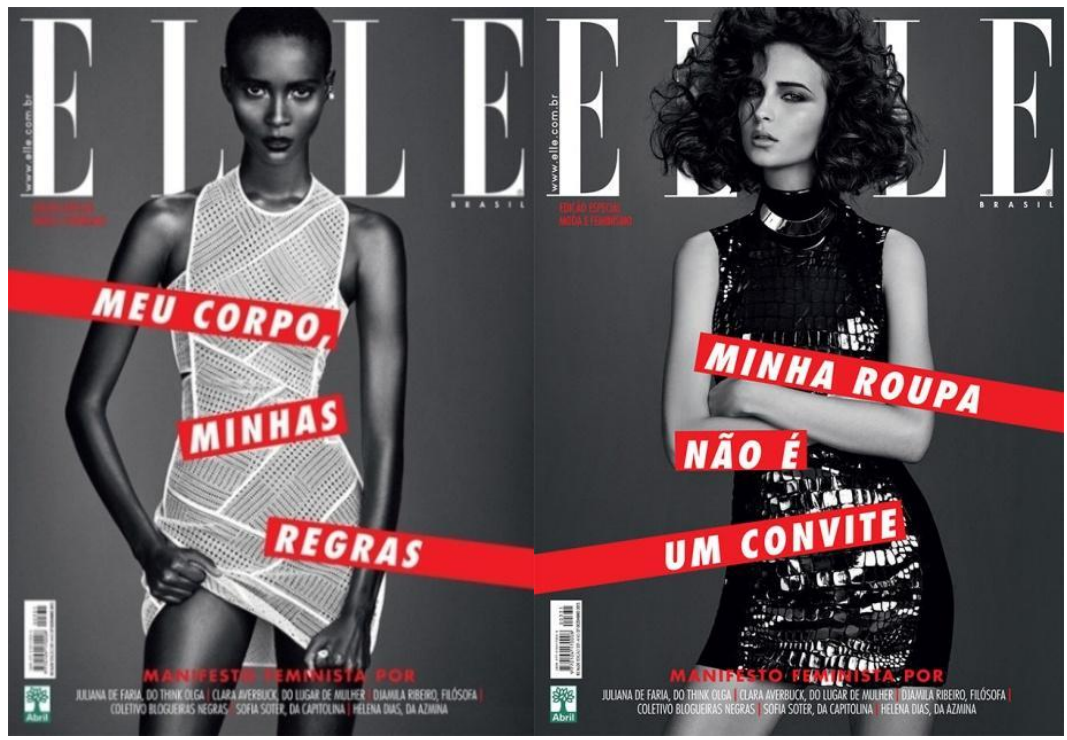

Capa C dez./2015; capa D dez./2015

O destaque da edição, classificada como "Especial Moda e Feminismo", foi o "manifesto feminista" escrito pelas jornalistas Juliana de Faria, Sofia Soter e Helena Dias, pela escritora Clara Averbuck, pela filósofa Djamila Ribeiro e pelo coletivo Blogueiras Negras. Dividido em tópicos, na forma de uma lista numerada, o manifesto foi produzido conjuntamente pelas convidadas. Cada colaboradora produziu sua lista individual abordando um viés diferente. A discussão começou com a temática "Por mulheres mais unidas", na fala da jornalista Sofia Soter, editora da revista Capitolina. Soter reivindicava o fim da rivalidade entre as mulheres, mais sororidade e colaboração com o trabalho feminino. Em seguida, Helena Dias, editora da revista AzMina, pedia o "Fim dos padrões de beleza", em sintonia com o tema principal da edição de maio.

Somos contra padrões de beleza irreais, que nos diminuem, controlam e adoecem para aumentar uma indústria que só tem a ganhar com nossa insegurança e um machismo que quer nos manter enfraquecidas. Queremos deixar claro que 
não devemos beleza ao mundo. Ela é apenas uma das muitas características que possuímos. Dizer que mulheres devem ser bonitas é só mais uma forma de nos manter inseguras e impedir que alcemos voos maiores. Queremos aceitar nosso corpo, nossa pele e nosso cabelo e poder nos amar como somos, em todas as variedades que nos tornam únicas. Nosso copo, nossas regras: A escolha de não nos depilarmos, não usarmos maquiagem, ou vestirmos determinadas roupas só diz respeito a nós mesmas. Não nos torna melhores nem piores que ninguém. Queremos o direito de envelhecer em paz, sem a exigência de uma pele e um corpo eternamente jovem. Pelo fim do uso do photoshop em nossas fotos, pois não precisamos ser diferentes do que somos (2015:60).

Depois foi a vez de Djamila Ribeiro, mestre em filosofia política, propor uma "Uma visão mais ampla da feminilidade". Em sua fala, Djamila priorizava questões referentes à maternidade compulsória e refuta a imposição de um padrão restrito do que é ser mulher. Juliana de Faria, fundadora da ONG Think Olga, discorreu pelo "Fim do assédio" e sobre violência diária vivida pelas mulheres nas ruas, dentro de casa e na internet. $\mathrm{Na}$ sequência, Clara Averbuck, do site Lugar de Mulher, demanda "igualdade no trabalho e direito ao próprio corpo", abrangendo temas como equidade salarial e direito à licença-maternidade livre de pressões de empregadores e colegas de trabalho. O coletivo Blogueiras Negras termina o manifesto exigindo que "as demandas das mulheres negras sejam ouvidas". Destaca-se o trecho em que o grupo diz: "Não admitimos mais sermos retratadas por estereótipos e de maneira eurocêntrica pela mídia e pela sociedade, apagando nossas vivências e nossa existência" (Elle, 2015:55).

Assim como na edição de maio de 2015, chama a atenção o fato de que, fora as seis reportagens e um editorial totalmente dedicados ao tema, a edição de dezembro contou com apenas 
dois conteúdos próprios alinhados ao feminismo ${ }^{4}$ em um conjunto composto por 35 matérias, entre reportagens e editoriais de moda. Outra ambiguidade que não passa despercebida é a questão de algumas das reivindicações presentes no 'manifesto feminista' irem contra o que a própria revista reproduz, como a imposição de padrões estéticos restritos $e$ a baixa diversidade étnica em suas páginas. Se por um lado Elle foi corajosa ao trazer questões pouco populares e disseminadas entre as mulheres e o que a sociedade as impõe, ela continuou a fazer direcionamentos cerceadores em questões de beleza e estética no resto da revista. Quando, no manifesto, Helena Dias ataca a padronização de beleza ou quando o coletivo Blogueiras Negras confronta os estereótipos recorrentes às mulheres negras, essas demandas ganham espaço incomum na imprensa feminina. Contudo, na sequência dessas críticas, a objetificação e a padronização estética da mulher logo reaparecem, reproduzindo aquilo que suas colaboradoras contestaram algumas páginas antes.

Essas contradições podem ser mais bem compreendidas pelo referencial construcionista da teoria do jornalismo, que articula os critérios de noticiabilidade (valores-notícia) com o contexto sociocultural em que a seleção das pautas ocorre, de forma a explicar como se dá a produção de notícias (newsmaking), ou seja, o que faz de alguns fatos notícias e outros não; e de que maneira esse processo contribui também para constituir coletivamente os fenômenos sociais (Traquina, 2005).

Segundo a hipótese do newsmaking, a notícia é definida como uma construção da realidade, em oposição à teoria do espelho, que acredita que ela é um reflexo do fato. Porém, a perspectiva de que o jornalismo constrói as notícias, não considera que elas sejam narrativas ficcionais e sem correspondência com a realidade exterior. Na verdade, como aponta Felipe Pena, esse

\footnotetext{
${ }^{4} \mathrm{O}$ editorial fotográfico "Só garotxs", com imagens de Fe Pinheiro, sobre a coleção masculina de verão da Gucci, de 2016, com roupas que subvertiam os limites dos gêneros; e a reportagem "A força está com elas", de Mariana Payno, sobre a personagem principal feminina do filme "Star Wars: O despertar da Força”.
} 
método "apenas enfatiza o caráter convencional das notícias, admitindo que elas informam e têm referência na realidade. Entretanto, também ajudam a construir essa mesma realidade $e$ possuem uma lógica interna de constituição que influencia todo o processo de construção" (2013:129).

Nesse sentido, Gaye Tuchman aponta que, apesar de serem construídas individualmente pelos jornalistas, as notícias resultam de uma produção rotinizada e serializada determinada pelas empresas jornalísticas, comparável a um processo industrial. Portanto, ainda que Tuchman acredite que notícias são como "histórias", os jornalistas não possuem autonomia incondicional em sua prática profissional, uma vez que eles precisam se submeter a um planejamento produtivo que responde em última instância à linha editorial da empresa (Tuchman, 1993).

Desta forma, é possível afirmar que o jornalismo pode atuar no modo como as pessoas percebem a realidade no mundo contemporâneo, visto que as notícias são parte de uma construção que varia segundo os profissionais que as produzem. Esta definição, no entanto, não exclui o fato de que diversos elementos como os valores-notícia, os limites impostos pelo tempo e a linha editorial do veículo influenciam a construção da própria notícia. Outro fator que demarca a atuação do jornalismo na percepção coletiva da realidade é a questão do agendamento, que atua diretamente na filtragem dos assuntos que serão pautados na rotina dos consumidores de notícias.

É preciso considerar assim os critérios de noticiabilidade (valores-notícia) do jornalismo e o contexto histórico em que as edições especiais de maio e dezembro de 2015 da revista Elle estão inseridas para poder entender as razões que a levaram à escolha do feminismo como tema principal.

No caso estudado, foi atendido o critério da 'atualidade', um dos valores-notícia mais importantes do jornalismo como categoria de constituição de seus produtos (Wolf, 2005). Ainda que este critério não seja tão relevante na imprensa feminina, em uma revista como Elle, que aborda majoritariamente conteúdos de moda, ele se torna quase obrigatório, uma vez que se referencia 
diretamente a mudanças de estilo e tendências de mercado. Assim, entende-se que, apesar da importância do movimento feminista, a escolha do tema por parte da publicação deveu-se mais ao contexto sócio-cultural do período do que a uma consonância com a linha editorial da revista, embora o contexto tenha proporcionado uma sensivel inflexão editorial, vide algumas edições seguintes de Elle Brasil.

Outros critérios próprios dos valores-notícia justificaram também a escolha do tema feminismo pela revista Elle. A 'natureza humana' da pauta, diretamente ligada aos movimentos sociais e aos direitos humanos, atenderia ao caráter substantivo do valor-notícia. $\mathrm{O}$ fácil acesso a fontes e ao local de ocorrência do fato responderia à categoria de valor-notícia relativa ao 'meio de informação'. Quanto ao 'público' da revista, é razoável supor que a pauta em questão esteja de acordo com os seus interesses (ainda que não seja uma de suas prioridades). Por fim, na categoria relativa à 'concorrência', identifica-se que a revista Elle, ao abordar o feminismo, conseguiu sair na frente em relação à sua principal concorrente, a revista Vogue Brasil.

Coincidentemente, em maio de 2015, a Vogue também apresentou sua edição especial de aniversário, mas escolheu os 20 anos de carreira da modelo brasileira Gisele Bündchen como temática desse exemplar, fazendo um contraponto com os 40 anos que a revista completaria naquele mesmo ano. Em dezembro de 2015, Vogue voltou a trazer a modelo Gisele Bündchen em sua capa, enquanto Elle distinguiu-se de sua concorrente ao selecionar um tema mais atual e mais relevante, mesmo correndo o risco de entrar em conflito com alguns de seus valores comerciais $e$ editoriais.

O fator 'tendência', de fato, aparece sempre como uma das principais características presentes em revistas de moda voltadas para o público feminino. Como argumenta Edgar Morin, o primeiro motor da moda é a necessidade de mudança em si mesma. O segundo é o desejo de originalidade pessoal por meio da afirmação dos sinais que identificam os pertencentes à elite (1997:142). Isto fica ainda mais evidente quando analisamos os 
dados que mostram a classe social do público de Elle no Brasil, formado majoritariamente por mulheres de classe alta e média, que enxergam a revista como uma espécie de manual de estética, de bom gosto e de estilo de vida.

As edições especiais de 2015 são particularmente relevantes porque trazem um conjunto de ambiguidades que contrastam com as edições regulares da revista, marcadas pela coerência editorial. Ainda que superficiais ou pouco consistentes, os discursos que questionam a beleza ideal, assumindo como possibilidade política a diversidade de corpos e formas, representa uma ruptura significativa para os padrões da revista. Tratar abertamente de violência sexual e racismo, numa sociedade marcada por negá-los cotidianamente; ou afirmar os direitos da mulher sobre sua saúde $e$ sua sexualidade igualmente representam pontos de inflexão naquela coerência editorial baseada na lógica da satisfação pelo consumo. Mas o quanto a exposição a essa agenda pode contribuir para a construção da subjetividade $e$ a formação ideológica, tendo em vista a possibilidade de estabelecer uma hegemonia cultural na sociedade quanto a formas sociais mais igualitárias para as mulheres?

Vale ressaltar que a posição de classe particular dessas mulheres está relacionada com um estilo de vida sintonizado com a ordem do consumo, na qual o corpo feminino é o espaço principal onde incidem uma série de regulações, imposições $e$ obrigações que vinculam o cuidado do corpo com seu aperfeiçoamento permanente, por meio de uma gama de produtos destinados a essa função (Wolf, 1992). A suspensão, ainda que parcial, da normatização possibilitada no âmbito do feminismo estilo magazine abre espaços para que os fatores que diferenciam essas mulheres de outras, mais suscetíveis à violência racial ou motivadas por fatores sócio-econômicos, e pode contribuir para a produção de uma sensibilização feminista, eventualmente capaz de gerar algum engajamento ideológico nesse grupo de pessoas. A chave analítica das diferenças proposta pela abordagem construcionista aqui se relaciona diretamente com o conceito de experiência entre o grupo de leitoras da revista. Como lembra 
Avtar Brah, a "experiência não reflete de maneira transparente uma realidade pré-determinada, mas é uma construção cultural. De fato, 'experiência' é um processo de significação que é condição mesma para a constituição daquilo que chamamos 'realidade"' (Brah, 2006:360).

Importa saber, é verdade, como as diferenças existentes no interior desse grupo (raça, gênero e sexualidade) afetam as experiências de constituição de novas identidades, considerando que a exposição ao debate feminista produz novas injunções culturais capazes de reconfigurar a subjetividade, proporcionando esclarecimento e sensibilização política.

A introdução da agenda feminista nesse grupo tem, portanto, o potencial de perturbar as formas convencionais de experiência. No entanto, como vimos, o conteúdo jornalístico é submetido a um planejamento produtivo que responde à linha editorial da revista, e que por sua vez atende, em última instância, aos interesses comerciais da empresa. A contradição entre a crítica feminista à alienação pelo consumo $e$ a promoção do consumismo pela revista feminina é resolvida por uma operação editorial de tratamento do feminismo que o enquadra no formato magazine, ou seja, caracterizando o que é movimento político como tendência ou modismo cultural, minando seu aspecto mais crítico e contestatório, sobretudo o de tipo radical ${ }^{5}$.

É certo que algumas correntes do feminismo confrontam diretamente os valores e os cânones da imprensa feminina tradicional. Porém, sua inserção se viabiliza se o feminismo puder ser tratado de forma genérica, como movimento cultural

${ }^{5}$ Feminismo radical é aqui compreendido como corrente teórica e movimento político autônomo de caráter revolucionário orientado para a liberação das mulheres. Entendidas a partir de uma concepção materialista, as feministas radicais apontam o patriarcado como a estrutura política e cultural que perpetua a dominação masculina em todas as esferas da vida das mulheres, sejam públicas ou privadas. Neste sentido, temas como reprodução, casamento, heteronormatividade e maternidade merecem atuação prioritária das radicais, visando transformações a partir de uma revolução das estruturas sociais e dos processos patriarcais. (Rowland; Klein, 1996) 
abrangente e sem matizes. Sob essa perspectiva pode então receber uma nova abordagem $e$ tornar-se um conceito comercialmente relevante, vendável, tratado como um modismo, em que o "engajamento político seria [reduzido a] um novo fetiche da mercadoria" (Silva, 2017:46). Essa roupagem contribui para esvaziar politicamente o movimento, negligenciando seus questionamentos diante da prevalência editorial da dimensão individual, do conforto dos bens materiais e da aquisição de coisas supérfluas como produto de comunicação de massa, na forma de commodity feminism.

A imprensa feminina assume com isso seu traço antipolítico, já que mesmo abordando questionamentos feministas, não consegue desenvolver uma revista alinhada com as demandas igualitaristas e pluralistas do movimento, uma vez que continua também a reproduzir padrões voltados para mulheres ajustadas. Das características da imprensa feminina tradicional, Elle guarda o sentido de aconselhamento, porém numa chave pedagógica sustentada numa filosofia de pseudo-emancipação. A leitora de Elle pode e deve ser aquilo que quiser, contanto que atenta às referências utilitárias do manual de estilo previsto pela publicação. Se por um lado Elle advoga a libertação dos padrões e a busca por independência, por outro segue investindo em representações normativas da mulher, salvo (e mesmo assim parcialmente, como vimos) nas edições de caráter excepcional. A baixa representação da diversidade e o traço antipolítico de revistas femininas, porém, precisa ser matizado quando temas como diversidade de gênero $e$ autonomia sexual ocupam suas páginas, muito embora a partir de colaboradoras, autoras que não compõem o quadro da revista. É sintomático que Elle precise importar profissionais de outros veículos, jornalistas engajadas em publicações declaradamente feministas, para dar conta de produzir uma edição sobre o tema, numa espécie de feminismo ad hoc.

Sobretudo na sociedade midiatizada, o desenvolvimento capitalista reencena a divisão sexual do trabalho sugerindo novas práticas sociais e novos significados, que renovam interpretações sobre o mundo para perpetuar diferenças sexuadas (Federici, 
2017), cujas empresas de mídia são instâncias privilegiadas da reencenação desses novos sentidos. Entretanto, transformações sócio-culturais da virada do século XXI permitiram às mulheres reivindicar e questionar os limites dos espaços antes consagrados exclusivamente aos homens. Assim, ainda que a revista Elle tenha utilizado o feminismo como uma tendência de moda e abordado o tema de maneira pouco aprofundada, a publicação proporcionou visibilidade ao movimento, levando-o a espaços e a públicos antes pouco ou quase inexplorados. $\mathrm{O}$ ganho do movimento feminista foi o destaque obtido em uma revista de ampla circulação e de conhecimento internacional, o que contribui para legitimá-lo como um assunto relevante até para os mais segmentos mais conservadores da sociedade.

$\mathrm{O}$ aporte teórico das interseccionalidades nos auxilia a compreender essa ambivalência. $\mathrm{O}$ feminismo estilo magazine, se por um lado mina a força da crítica contra padronização estética e comportamental e contra a alienação consumista, por outro lado expõe a complexidade das posições de classe, raça e gênero consolidadas no extrato das consumidoras de Elle. A categoria individual 'mulher' não é internamente homogênea $e$ a abordagem midiática produzida por Elle permitiu evidenciar comunalidades nas diferenças, tanto em relação às formas de dominação comuns quanto em relação às articulações singulares de outras categorias, como raça, gênero e credo.

Ao escolher tratar do feminismo, a revista Elle mostrou que estava atenta à crescente aderência por parte de suas leitoras (mas também de seus anunciantes), e não apenas à afinidade que os profissionais que trabalham na publicação têm com o tema. $\mathrm{Na}$ edição de maio de 2015, por exemplo, mesmo lidando diretamente com a temática da representatividade, pauta historicamente ligada ao movimento feminista, a publicação não deixou esse vínculo claro e, como explicou a diretora de redação da publicação, Susana Barbosa, a ideia da edição especial era "homenagear quem está no centro da moda: as mulheres". Com essa postura, a revista se esquivou de um compromisso, eximindose da responsabilidade política com as demandas do movimento. 
Na edição de dezembro, por sua vez, Susana Barbosa voltou a tratar de feminismo, dessa vez de forma clara e objetiva, embora em alguns momentos ambígua. Em uma carta às leitoras, ela escreve:

Sendo ELLE uma revista feminina, me senti na obrigação de fecharmos o ano engrossando o coro de um assunto que nos toca diretamente $e$ nunca esteve tão em pauta: a tomada de consciência sobre o feminismo. E como retratar isso em uma revista de moda? Ela, vilã, não seria o oposto dessa história? Escolhemos estampar na capa a voz das ruas, com frases que foram extraídas dos cartazes usados nas grandes manifestações feministas mais recentes. A maioria delas fala sobre a imagem $e$ o vestir femininos coisa que tem tudo a ver com a gente (e com você, mesmo que ainda não tenha parado para pensar nisso). Se há uma revista de moda que pode falar com consistência sobre esse assunto é a ELLE, que tem o feminismo no seu DNA. Desde que foi criada na França, ela incentiva a mulher a se libertar dos padróes, buscar independência, ter personalidade própria $e$ lutar pelo seu espaço. Aqui, no Brasil, não tem sido diferente. Para ir além da moda e das quatro capas statement que criamos, convidamos algumas das representantes dos principais movimentos feministas brasileiros (...) a criar um manifesto com as reivindicações mais importantes. A ideia é juntar forças e unir nossas vozes porque acreditamos que \# juntassomosmais. (...) Afinal, o que uma revista de moda (que sempre ditou regras e padrões) estava se propondo a fazer ao entrar nessa seara? Vender uns exemplares a mais ao surfar na onda de um movimento sério como esse? Historicamente, revistas de moda são, sim, uma das grandes responsáveis pela "objetificação" da mulher por impor padrões de corpo, pele e cabelo, por fechar os olhos (ou as páginas, melhor dizendo) à diversidade. Não podemos negar que por aqui nós também já caímos nessa armadilha. E temos nos policiado para, a cada edição, manter a coerência entre o discurso e a prática. (...) Me orgulho de dizer que há alguns anos a ELLE Brasil está tentando escrever uma nova história e abrir espaço para outra conversa. (...) Em 2013, 
publicamos na capa a modelo Georgia Jagger com a chamada Girl Power. Considero que essa tenha sido nossa primeira edição feminista. Ali, a própria Juliana Faria escrevia sobre o neofeminismo, "que libera a mulher para ser fashion e sensual, casar virgem, pintar o cabelo, batalhar pelos seus direitos, rebolar ou não fazer nada disso. $\mathrm{O}$ importante é ter liberdade de escolha". De lá para cá, abrimos espaço para a então desconhecida JoutJout, quebramos a internet com a foto da blogueira plus size Ju Romano nua em uma de nossas capas digitais, colocamos \#vocênacapa espelhada da edição de aniversário e ainda três leitoras de idades e tipos físicos diferentes (na capa de junho deste ano, lembra?).

Para uma revista de moda, não é só uma evolução, mas uma revolução. Grupos de todos os tamanhos estão se organizando para discutir a questão do feminismo e da diversidade online porque - thank God! - a internet possibilitou esse diálogo amplo e aberto. Se por um lado, como mídia impressa, sempre fomos acusadas de impor padróes - e durante anos tivemos mesmo esse poder -, por outro, está mais do que na hora de usar o alcance que temos em todas as nossas plataformas para contribuir de alguma forma para esse diálogo sobre a mudança. Queremos participar e incentivar essa conversa. Porque acreditamos que o mundo mudou e só existe um caminho: você pode ser agente da mudança ou ficar em sua zona de conforto e ser atropelada por ela. Impossível é tentar contêla ou ignorá-la. Espero que você venha com a gente! (Elle Brasil, 2015b:44, grifo nosso).

Pode-se notar que Susana Barbosa faz um mea-culpa ao responsabilizar a publicação por seguir e adotar um padrão estético e moral durante tantos anos. Porém, a diretora entra em contradição ao afirmar que a revista Elle tem "o feminismo em seu DNA", já que no próprio texto a diretora deixa claro que, historicamente, revistas de moda são responsáveis pela objetificação da mulher. Ainda que discreto, há um ganho ao movimento feminista. A declaração de compromisso da revista com a mudança foi significativa, mais alinhada com o crescimento 
do debate na sociedade em geral; e na moda e na publicidade, em particular. Além das edições de maio e dezembro de 2015, objetos deste artigo, a revista chegou a dar destaque a outros problemas relativos à condição feminina bem como à diversidade de gênero.

Em dezembro de 2011, a capa foi ocupada pela modelo transexual Lea T. Na edição de aniversário de 2016, a capa trouxe como modelo a refugiada africana Alek Wek, quando a revista a entrevistou e pôde destacar o problema da violência contra a mulher no contexto de guerra civil no Sudão do Sul. Em julho e em novembro de 2016, Valentina Sampaio, outra modelo transexual, ocupou a capa da edição brasileira. Finalmente, a edição comemorativa de aniversário de maio de 2017 teve como tema o amor trazendo três capas distintas. A primeira apresentava seis diferentes tipos físicos de mulheres (embora prevalecessem brancas) abraçadas e deitadas umas sobre as outras em uma composição colorida que destacava a diversidade. A segunda capa trouxe um casal feminino em uma foto marcada pela delicadeza de expressão de afeto, escapando do romantismo heteronormativo, ainda que essa mesma delicadeza pudesse também reiterar um tipo de feminilidade. A terceira, no entanto, representava o chavão do príncipe encantado com a modelo Thairine Garcia simulando um beijo em um sapo. Em seu perfil no Instagram, a editora Susana Barbosa destacou o trabalho confirmando a ambiguidade da proposta: "Princesa Elle não acredita em príncipes, afinal estamos em 2017. Pero que los hay, los hay! É muito amor por uma capa!" (Barbosa, 2016:n.p.).

Esses exemplos apontam que a revista Elle mobilizou o tema do feminismo ao mesmo tempo em que promovia tendências de moda, sem desvincular-se totalmente de um padrão reproduzido pela imprensa feminina desde sua origem. Isso ocorre, entre outras razões, porque as revistas de moda são mercadorias culturais que não estão comprometidas com a promoção de reflexão e de crítica. Como produto da cultura de massa, que têm interesse em homogeneizar pensamentos $e$ atitudes orientados para o consumo, essas publicações cumprem um papel de formação, ao promover um atraente estilo de vida elitista. Sendo assim, quando 
Elle Brasil escolhe abordar o feminismo, não pretende afinar ou alterar sua linha editorial, mas tratar do que é atual na sociedade, do que está sendo dito e considerado por suas leitoras. Com isso, a revista reafirma seu lugar no contexto cultural, filtra e concebe um conceito próprio para seu público, de forma a não ofender seus interesses comerciais.

\section{Considerações finais}

Mesmo com ambiguidades, importantes decisões editoriais levaram a revista Elle Brasil a enfatizar temas pertinentes ao feminismo, ainda que não em sua complexidade. Uma comparação entre a edição de maio de 2015 e a de maio de 2017 mostra que o número de reportagens alinhadas ao debate feminista continuava reduzido. Tanto quanto na edição de 2015, a de 2017 trouxe apenas sete matérias com temáticas feministas num universo de 40 . O número reduzido evidencia que o feminismo, apesar das bem intencionadas declarações editoriais, não dispunha de espaço relevante.

Essa contradição aparente pode ser compreendida porque experiências como a que Elle promoveu esbarraram na concepção fundamental que sustenta revistas de moda luxo, um compromisso com valores de mercado e de consumo anteriores e contraditórios com os valores defendidos pelo movimento feminista (como a crítica à alienação pelo consumo e à normatização do corpo segundo ideais prescritos de beleza, por exemplo). O circuito de legitimação do mercado (Morin, 1989) exige que a revista siga alimentando, através da criação ou fomento de tendências, a dinâmica cultural baseada no consumo, necessária para a manutenção dos ciclos de produção capitalista. Revistas de moda anunciam basicamente produtos de beleza, roupas e serviços estéticos, e a grande maioria das reportagens prioriza assim a reprodução de padrões de comportamento restritos, alinhados aos interesses comerciais de seus anunciantes.

Está claro que além de serem veículos jornalísticos, revistas femininas são também importantes vetores da publicidade. Seu 
caráter de segmentação facilita que os anunciantes atinjam o público desejado. No contexto do ano de 2015, questões relacionadas ao feminismo alcançaram o vestibular no Brasil e as redes sociais, campanhas publicitárias, desfiles de moda e a indústria fonográfica. Pela relevância adquirida pelo movimento, tornou-se mais difícil, mesmo no sentido comercial, que a revista Elle não tratasse do assunto. Afinal, era preciso também estar alinhada não só com a atualidade, mas com seus próprios anunciantes.

Mas as edições especiais de Elle Brasil significaram inflexões sem alterações do tom geral da revista, que seguiu sendo majoritariamente conservadora e superficial. Nesse contexto, o feminismo deve ser algo especial, excepcional, dentro de um engajamento seletivo e oportunista, em que as tecnologias de produção de gênero respondem pela construção de discursos que absorvem as provocações $e$ os avanços do movimento, assimilando-os sob formatos atualizados, adaptados à "mulher moderna", profissional inserida no mercado de trabalho sem que seu papel tradicional seja substituído.

$\mathrm{O}$ feminismo estilo magazine se traduz assim mais como uma atitude e fenômeno da contemporaneidade do que como uma expressão política de um grupo em busca de igualdade, respeito e reconhecimento. Ele pode ser caracterizado ainda como uma atualização de vínculos reconhecidos em outros momentos da imprensa feminina brasileira. A perspectiva construcionista do jornalismo considera que a imprensa trabalha com o que está acontecendo na sociedade e, ao fazê-lo, colabora para de alguma forma reconfigurá-la. Revistas como Elle pretendem ser referências dos costumes de uma época, embora as formas de comportamento não sejam constituídas exclusivamente no interior da sociedade, de maneira autônoma. Esses fenômenos comportamentais, no entanto, se constituem em interação com a influência dos meios de comunicação na cultura, na forma de tendências de consumo, majoritariamente.

Este artigo compreende que a publicação teve como compromisso último a fidelidade aos seus interesses comerciais, 
ainda que esses, por vezes, pudessem soar contraditórios. Por outro lado, expressar, evidenciar e denunciar deve ser parte da estratégia de reconhecimento da questão das diferenças e de como isso implica em assimetrias políticas e diferentes formas de violências contra as mulheres. Falar do feminismo é expor, mesmo que de forma ambígua, as opressões a que são submetidas as mulheres, no contexto de uma disputa por exposição $e$ legitimidade de pautas. Atentar para as interseccionalidades da condição feminina permite entender que a visibilidade garantida pela publicação pode haver proporcionado articulações com um grupo de mulheres que se encontravam distanciadas politicamente do feminismo. Essa visibilidade ocasionada pelo feminismo estilo magazine pode favorecer o movimento na produção de legitimidade e de hegemonia ideológica. Assim, mesmo abordado de maneira pouco aprofundada, o feminismo como movimento cultural pôde atingir mais espaços, despertar interesse em um público maior e se legitimar no meio da grande imprensa e entre a própria opinião pública brasileira.

\section{Referências bibliográficas}

BANDEIRA, Ana Paula Bornhausen da Silva. Jornalismo feminino e jornalismo feminista: aproximações e distanciamentos. Vozes $e$ Diálogos, Itajaí, v.14, n.2, julho-dezembro, 2015.

BuITONI, Dulcilia Schroeder. Imprensa feminina. São Paulo: Ática, 1986.

BUITONI, Dulcília Schroeder. Revistas femininas: ainda somos as mesmas, como nossas mães. Revista Communicare - Dossiê Feminismo, v.14, n. $1,1^{\circ}$ semestre, 2014.

BRAH, Avtar. Diferença, diversidade, diferenciação. Cadernos pagu, São Paulo, v.26, janeiro-junho, 2006.

CAHILL, Ann J. Overcoming objectification. New York, Routledge, 2012.

DUARTE, Constância Lima. Imprensa feminina e feminista no Brasil: século XIX - Dicionário ilustrado. Belo Horizonte: Autêntica, 2016.

FEDERICI, Silvia. Calibã e a bruxa: mulheres, corpo e acumulação primitiva.São Paulo: Elefante, 2017. 
Goldman, Robert; HEATH, Deborah; SMITH, Sharon L. Commodity Feminism. Critical Studies in Mass Communication.Londres: Routledge (8), 1991.

HALL, Stuart. A identidade cultural na pós-modernidade.Rio de Janeiro: Lamparina, 2014.

KARHWAI, Issaaf. Influenciadores digitais: o Eu como mercadoria. In: SAAD, Elizabeth; SILVEIRA, Stefanie Carlan da (Org). Tendências em Comunicação Digital. São Paulo: ECA-USP, 2016.

Kellner, Douglas. A cultura da mídia. Bauru: Edusc, 2001.

LIMA, Samanta Petersen da Rocha; SAID, Gustavo Fortes. Revistas para mulheres e os modelos identitários femininos em uma sociedade em midiatização. In: Seminário Internacional De Pesquisas Em Midiatização E Processos Sociais. 2, 2018, São Leopoldo. Anais... São Leopoldo, Unisinos, 2018.

MoRIN, Edgar. As estrelas: mito e sedução no cinema. Rio de Janeiro: José Olympio, 1989.

Morin, Edgar. Cultura de Massa no século XX: neurose. Rio de Janeiro: Forense Universitária, 1997.

Orozco, Guilhermo G. Comunicação social e mudança tecnológica: um cenário de múltiplos desordenamentos. In: MORAES, Dênis de (Org.). A Sociedade midiatizada. Rio de Janeiro: Mauad, 2006.

PENA, Felipe. Teoria do jornalismo. São Paulo: Contexto, 2013.

PISCITELli, Adriana. Interseccionalidades, categorias de articulação e experiências de migrantes brasileiras. Sociedade e Cultura, v.11, n.2, jul/dez., 2008.

REED, David. 'Rise and shine!': the birth of the glossy magazine. The British Library Journal, v. 24, n. 2, 1998.

RowlAND, Robyn; KLEIN, Renate. Radical feminism: History, politics, action. In: BELL, Diane;KLEIN, Renate (ed.) Radically Speaking. Melbourne: Spinifex, 1996, pp.9-36.

SCALzo, Marília. Jornalismo de revista. São Paulo: Contexto, 2014. 
SILVA, Ana Beatriz Rangel Pessanha da. Comunicação e Gênero: as narrativas dos movimentos feministas contemporâneos. 2017, 98 f. Dissertação de Mestrado, Comunicação Social, UFRJ, 2017.

SILVA, Ana Beatriz Rangel Pessanha da. Da revista feminina à revista feminista: entre o correio sentimental e a militância terapêutica. Entremeios, v.13(1), 2016.

SwAIN, Tania Navarro. Feminismo e recortes do tempo presente: mulheres em revistas 'femininas'. São Paulo em Perspectiva, 15(3), 2001.

TOMAZETTI, Tainan Pauli. O feminismo na era digital e a (re)configuração de um contexto comunicativo para políticas de gênero. Razón y Palabra. México: Editorial Razón y Palabra, n. 90, 2015.

TRAQuina, Nelson. Teorias do Jornalismo. Porque as notícias são como são. Florianópolis: Insular, 2005.

TUCHMAN, Guye. La producción de la noticia: estudio sobre la construcción de la realidade. Barcelona: Bosch, 1993.

Wolf, Mauro. Teorias da comunicação de massa. Rio de Janeiro: Martins Fontes, 2005.

Wolf, Naomi. O mito da beleza. Rio de Janeiro: Rocco, 1992.

\section{Material de campo}

BARBOSA, Suzana. Disponível em: $<$ https://www.instagram.com/p/BTrnL6RF7_C/.>. Publicado em 4 de maio de 2017. Acesso em: 15 de ago. 2017.

Elle Brasil. São Paulo: Ed. Abril, ano 27, n. 324, maio, 2015.

ELLE Brasil. São Paulo: Ed. Abril, ano 27, n. 331, dezembro, 2015.

MÍDIA Kit Elle 2017. São Paulo: Ed. Abril, 2017. Disponível em: <http://publiabril.abril.com.br/midia kits>. Acesso em: 27 ago. 2017 